\title{
Improving Productivity in the Manufacturing Industry by using Industrial Engineering Tools and techniques
}

\author{
Ashwini Dongre, Archana Bhange, Abhilahsha Dhamdhere, Venugopal Kulkarni
}

\begin{abstract}
Planning and designing of manufacturing processes and material handling equipment are effective, helps to achieve maximum productivity through maximum utilization of the available resources. This paper aims to study the implementations of industrial engineering tools in the manufacturing industry. At the same time, the observations by visiting the industry were made to identify the problems, so that we can make possible improvements. Time study and Layout study techniques helps us to identify and rectify the time lost in unnecessary and unproductive travelling movements of labor and tools. After observing the problems The proposed layout was suggested and Some easy and time effective material handling equipment were suggested. Which helps to increase productivity.
\end{abstract}

Keywords: Method study, Plant layout, Facility Planning, Material Handling Equipment, Productivity.

\section{INTRODUCTION}

This project was taken up in the Royal Engineering and Solutions which is located at the Bhosari MIDC Pune. It is a medium scale manufacturing based company. There was an excellent opportunity to learn about the actual manufacturing processes. Nowadays product demand is increasing, to fulfill the demand that the industry must increase their productivity. Productivity refers to the relationship between the quality produced and the number of resources used in the production i.e. the ratio between the output of goods and the input of resources used in the process of production.

productivity can be improved by using a technique such as time study, method study, and design of plant layout. Plant layout, human body, method of production, material handling equipment, tool storage, etc. all this thing are effects on the productivity of the industry. So, we observed all this thing and find out the solutions which can help to reduce the wastage of time, place, material, etc. and helps to increases in productivity of the industry.

The problems that we were able to mark are as follows:

1. Stacking of Raw material.

Revised Manuscript Received on June 22, 2020.

* Correspondence Author

Ashwini Dongre*, School of Mechanical and Civil Engineering.MIT Academy Of Engineering,Pune. Email: aldongre@mitaoe.ac.in

Archana Bhange, School of Mechanical and Civil Engineering.MIT Academy Of Engineering,Pune. Email: asbhange@mitaoe.ac.in

Abhilasha Dhamdhere, School of Mechanical and Civil Engineering.MIT Academy Of Engineering, Pune Email: abdhamdhere@mitaoe.ac.in

(C) The Authors. Published by Blue Eyes Intelligence Engineering and Sciences Publication (BEIESP). This is an open access article under the CC BY-NC-ND license (http://creativecommons.org/licenses/by-nc-nd/4.0/)
2. Combined sections of two departments created disturbance for each of the departments.

3. Unproductive travel takes extra time than required.

4. Inappropriate material handling equipment.

5. Unplanned and improper Plant layout.

To overcome all these problems the change of layout was necessary as many problems are created due to improper arrangement of facilities. Also for the satisfaction of employees, the modification in material handling equipment was required.

\section{Objectives of the Research:}

- To identify areas of productivity improvement.

- To have a higher level of output by using efficient material handling equipment.

- To reduce Unproductive lengthy travel.

\section{II.METHODOLOGY}

I.

CHANGE OF LAYOUT

Plant Layout or Proper arrangement of all the facilities is a very important part of a company or any type of industry. In the plant layout, all the facilities should be arranged effectively and efficiently. There should be a minimum material handling during two operations as well as minimum material handling distance, there should be straight passages with minimum backtracking, Flow pattern should be planned, etc. In this company, there are a total of eight sections i.e. Raw material and machining section, Tool manufacturing, Main office, and design department, Final product storage, Product assembly section, Washing, Inspection, and shipping area.

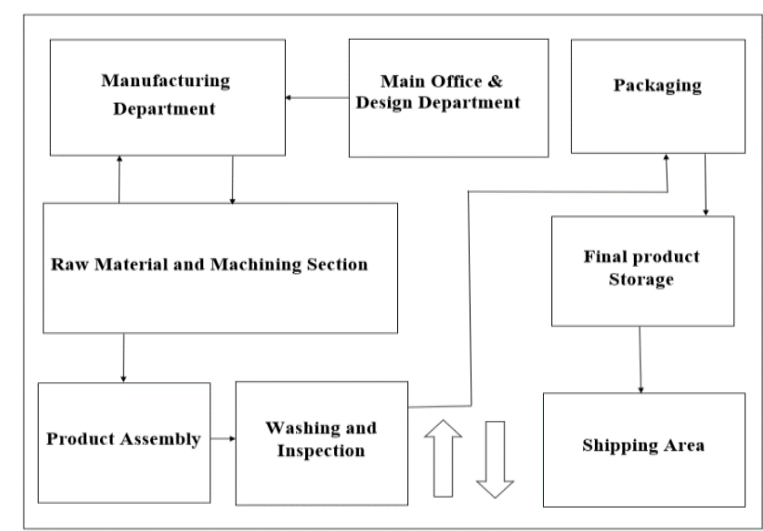

Fig 1- Existing Layout

Published By:

Blue Eyes Intelligence Engineering

\& Sciences Publication

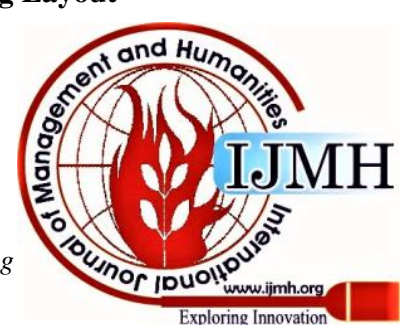




\section{Improving Productivity in the Manufacturing Industry by using Industrial Engineering Tools and techniques}

In this company, the disturbance is created due to combined sections of two departments, as there is one combine section for the Raw material and machining department, a combined section for the design department and main office as well as Washing and Inspection.

This combined section creates a disturbance in the work of both of the departments Also Stacking of raw material also occurred. Which can result in a delay in the work. So, this improper arrangement of facilities and delays in work may affect productivity. According to the current layout, there is only one way for entry and exit which creates a blockage. There should be separate sections for every department and separate ways for entry and exit. So, it can help in improving productivity.

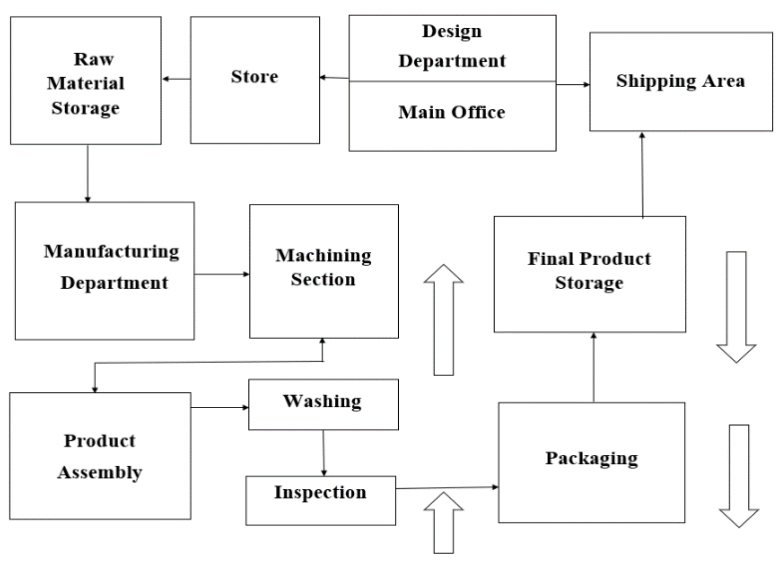

Fig 2- Proposed layout

The arrangement of facilities, machines, material, etc. is defined as the Layout. In terms of increasing productivity of any company the plant, layout plays a very important role. In the proposed layout all the sections are closely placed together to eliminate all the unnecessary travel.

Following results are recorded before and after proposed layout:

\begin{tabular}{|l|l|l|}
\hline & Before & After \\
\hline Total distance traveled & $118 \mathrm{~m}$ & $98 \mathrm{~m}$ \\
\hline $\begin{array}{l}\text { The average speed of the } \\
\text { worker }\end{array}$ & $0.8 \mathrm{~m} / \mathrm{s}$ & $0.8 \mathrm{~m} / \mathrm{s}$ \\
\hline Time required & $147.5 \mathrm{~min}$ & $122.5 \mathrm{~min}$ \\
\hline
\end{tabular}

Total time saved $=147.5 \mathrm{mins}-127.5 \mathrm{mins}$

$$
=25 \text { mins }
$$

\section{i. Changing Material handling equipment}

In industry, containers are used to store the tools. All types of tool i.e. tool of different size shapes are in one container so it takes much time to find out tools from that container as it is a wastage of time.

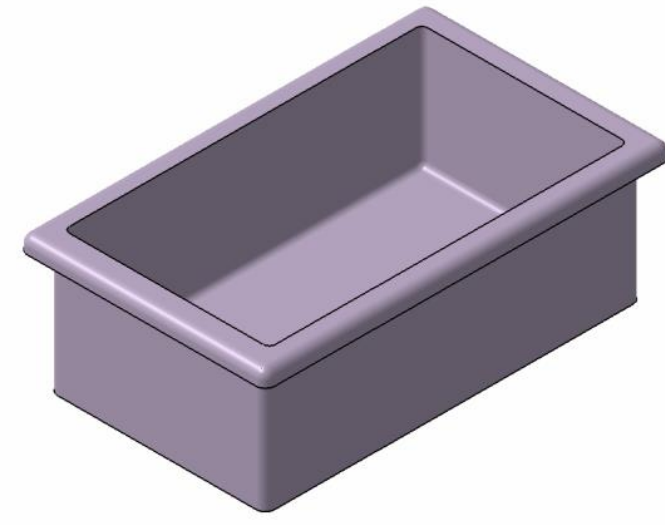

Fig 3- Container

We are proposing a solution as a shelves with two different compartments in which small trays are mounted. Tool racks are used to store and organize tools in an exposed manner so that tools are easy to identify, retrieve, and return. Tools of different sizes and types are placed in a different compartment so it is easy to find out tools at the time of requirement. I use this rack for storing tools it decreases the wastage of time for finding tools and hence productivity increases.

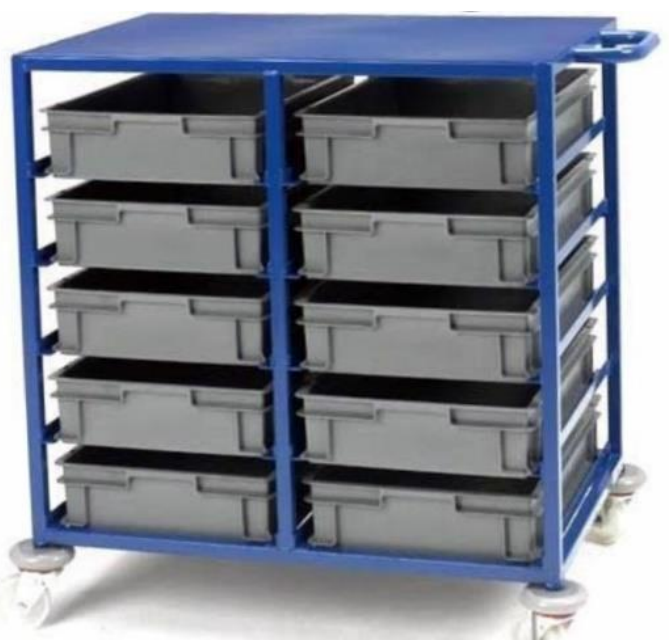

Fig 4- Shelves

Currently, the dolly is used to move the finished goods or products from one position to another. To move the dolly worker has to bent and then push it required lots of energy. Sometimes product collapses out of the dolly.

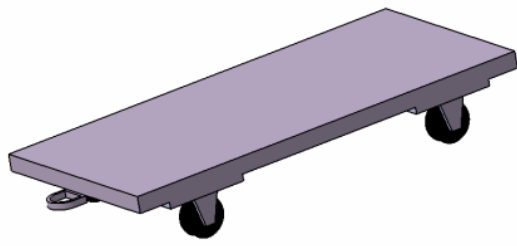

Fig 5 - Dolly

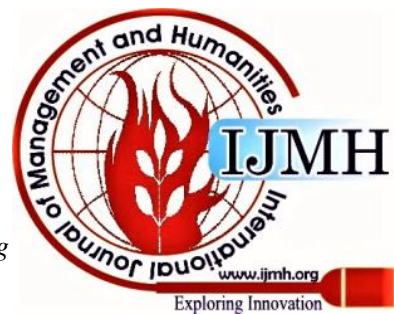


The proposed solution is a floor hand truck. It has two handles which help to move the truck easily. The worker does not need to bend to push the truck. The truck has two walls due to this product does not fall. It reduces the fatigue of the product and increases load-carrying capacity. The truck is narrow and fall, vertical handles are preferable as it allows a comfortable height for all users.

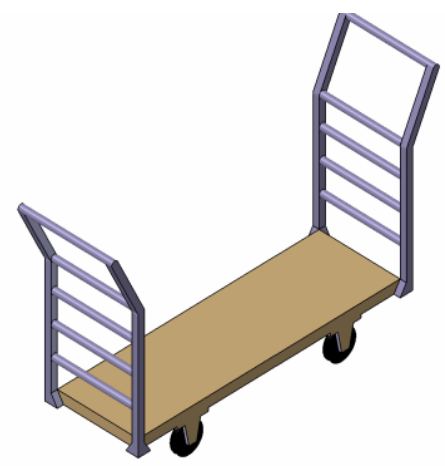

Fig 6 - Floor Hand Truck

ii. Productivity Increment.

Table 2 Productivity Increment

\begin{tabular}{|l|l|l|}
\hline & Existing & Proposed \\
\hline Cycle time for one job & $210 \mathrm{sec}$ & $204 \mathrm{sec}$ \\
\hline Parts made & & \\
\hline Profit/part & 14000 & 17080 \\
\hline Total turnover & 400 & 400 \\
& & $68,32,000$ \\
\hline
\end{tabular}

Hence,

Total profit made $=68,32,000-56,00,000$

$$
=\text { Rs.12,32,000. }
$$

Profit Increment $=12,32,000 / 56,00,000$

$$
=22 \%
$$

Thus, by the application of Proposed facility planning techniques the productivity can be improve by $22 \%$

\section{CONCLUSIONS AND DISCUSSIONS}

Increase in productivity is depends on the effective planning and design of equipment, plant layout, and material handling equipment. From this study We can conclude that existing state of layout and material handling equipment are time consuming and inefficient. We Proposed other best method which helps to improve productivity. Changing the existing the material handling equipment with proposed one, requires less time and less effort. Also by applying proposed layout we can save the unnecessary unproductive travel time by 25 mins. By applying all these proposed methods we can increase the productivity by approximately $22 \%$.

For progress in any industry, it is required to identify the various factors that influence the growth. There were some

other modifications are suggested such as making a separate store room to keep the equipment's and tools which are required in various sections, but this required a large capital investment so we keep it out of this study. So this study indicates towards betterment by applying efficient Industrial engineering and Facility planning tools and techniques.

\section{REFERENCES}

1. "Improving Productivity in a Paint Industry using Industrial Engineering Tools and Techniques" Aakash Jaiswal, Shriram Madhukar Sane, and Varsha Karandikar. International Journal of Advance Industrial Engineering. Accepted 28 March 2016.

2. "Productivity Improvement by Optimum Utilization of Plant Layout" Akshay D. Wankhade1, Dr. Achal S. Shahare.International Research Journal of Engineering and Technology (IRJET) Volume: 04 Issue: 06 | June -2017

3. "PRODUCTIVITY IMPROVEMENT BY USING METHOD STUDY IN AUTOMOBILE INDUSTRY: A CASE STUDY" Prof. Ravi Nagaich, Dr. Apratul Chandra Shukla, Rishabh Mishra. Vol. X \& Issue No. 9 September - 2017.INDUSTRIAL ENGINEERING JOURNAL

\section{AUTHORS PROFILE}

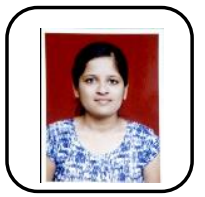

Ashwini Dongre, A student pursuing BTech in Mechanical Engineering in MIT Academy of Engineering, Pune from 2018. Completed Diploma in Mechanical Engineering from Cusrow wadia institute of Technology,Pune with first class Distinction. currently working on Multi-directional conveyor belt system project and Stress Analysis of Tapping tool. Had one month internship in bharat forge limited. She was involved in projects like multipurpose drilling machine.

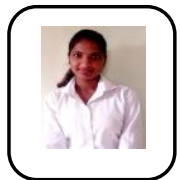

Chakan, Pune.

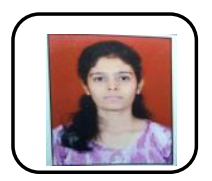

project

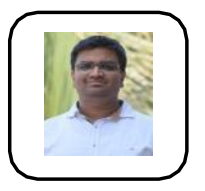

Archana Bhange, A student pursuing BTech in Mechanical Engineering in MIT Academy of Engineering, Pune from 2018. Completed Diploma in Mechanical Engineering from Government Polytechnique Solapur Currently working on Peltier Fridge project. She was involved in IOT based garbage monitoring system and Wireless vision camera. Internship in USA Engineering

Abhilasha Dhamdhere, A student pursuing BTech in Mechanical Engineering in MIT Academy of Engineering, Pune from 2018. Completed Diploma in Mechanical Engineering from Cusrow wadia institute of Technology,Pune with first class Distinction. currently working on Multi-directional conveyor belt system

Venugopal Kulkarni Working as Assistant Professor in MIT Academy of Engineering, Pune from June 2016. Associated with Institution of Mechanical Engineers (IMechE), UK since December 2016. Working as Industrial consultant in Chakan, Pune Industrial area for activities like training, quality since 2016.
Published By: Blue Eyes Intelligence Engineering \& Sciences Publication (C) Copyright: All rights reserved.

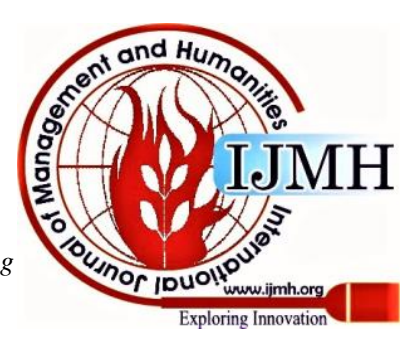

